\title{
IMPACT OF SOCIAL MEDIA USAGE AND ACTIVE COLLABORATIVE LEARNING ON STUDENT ENGAGEMENT, SATISFACTION, AND LEARNING PERFORMANCE: GHANA AS GEOGRAPHIC AREA OF STUDY
}

\author{
Clarissa Oteng - Darko*1, Fan Ming Yue ${ }^{2}$, Otu Larbi-Siaw ${ }^{3}$ \\ ${ }^{1,2,3}$ School of Management, Jiangsu University, 301 Xuefu Road, Jingkou-Zhenjiang, Jiangsu Province, \\ China 212013.
}

*Corresponding Author

Article DOI: https://doi.org/10.36713/epra8416

DOI No: 10.36713/epra8416

\begin{abstract}
This research aims to explore how social media use improves higher level education in Ghana.

Emphatically, it attempts to investigate the effect of social media use and active collaborative learning on student engagement, satisfaction and learning performance. A close-ended questionnaire was administered through online survey to collect data from 429 higher education students. The relationship between variables were tested using partial least square structural equation modeling (PLS-SEM). The research findings involve the significant effect of social media usage and active collaborative learning on student engagement, satisfaction, and learning performance. As per result development, student engagement positively affected satisfaction, which in turn influences learning performance. Moreover, this study concludes that effective use of social media, active collaborative and student engagement via social media enhances learning and satisfaction. The present study also offers several theoretical and practical implications for educational institutions and research directions for upcoming scholars.
\end{abstract}

KEYWORDS: Social media use, active collaborative learning, student engagement, student satisfaction, student learning performance.

\section{INTRODUCTION}

Although, several studies have been explored on how new technologies could enable educational process (Aldahdouh et al., 2020), technologies have been promoted as assisting with teaching, facilitating research collaboration (Al-Daihani et al., 2018), and supporting students learning (Manca \& Ranieri, 2017), as well as improving staff professional development (Deshpande \& Shesh, 2021). Accordingly, the constant advancement in online technologies is reshaping the way the field of academia communicates, connects and collaborates with diverse partners (e.g., students, their parents, teachers, and donors). To support and promote these interactions social media has become a fall-on platform to birth and sustain this course. Social media consists of photo, video, bookmarking and social networking sites, wikis, and discussion forums (Sikandar Ali Qalati, Dragana Ostic, et al., 2021). Since December 2019, when the epidemic-turnedpandemic (COVID-19) hit and drastically changed the lives of every single being, also forced educational institutions of all levels and scope to shift from the traditional form, that is, face-to-face education to online. Although, educational institutions operating in developing countries often do not have adequate resources and reliable, non-interruptive access to formal online learning system (Sobaih et al., 2020), social media is making it possible as it opens new and cost-efficient avenue for academics to improve education by publicizing their work, and engaging with stakeholders (Chugh et al., 2021). However, simply 
using social media tools does not guarantee that students and academic staff are effectively and efficiently using it (Aldahdouh et al., 2020).

Globally, there are over 3.8 billion social media users (Chugh et al., 2021) and estimated to be more than 4.41 billion (Department, 2021) which corresponds to over half of the world population (Sikandar Ali Qalati, Esthela Galvan Vela, et al., 2021) and includes students, and academic staff at different educational levels: students of different degree level, ages and experiences actively utilizing social media tools to search session lectures, research collaboration, share information, improve their interaction with others, whereas teachers in higher education institutions are using social media applications to promote their research work, contribute to wider line of conversation and enable the public (i.e., students, government, and other scholars) as a whole to actively participate in construction of knowledge (Pausé \& Russell, 2016). In addition, prior work also evidenced that social media use in higher education support the communication and interaction with students, enhance their learning experience, and supplement traditional learning (Sobaih et al., 2020). Moreover, it enables the students to develop, innovate, interact, and share content of course relatable to them in text, audio, and video form (Ansari \& Khan, 2020). However, at the same time few scholars evidenced that the area of academia would rather set aside the use of social media or even when in use, exploit it the bare minimum possible, this is as a result of the conflicts between the clear cut benefits of the use of social media as against its shortcomings that these institutions may face and also cultural restrictions that poses itself as a mind distraction and other pedagogical and pragmatic reasons (Manca \& Ranieri, 2016; Maryanti et al., 2021; Montazer \& Al-Rikabi, 2021).

Admittedly, social media use equips educational institutes and its user's performance, but it is clear that this may not be the case consistently and extensively, and the existing literature presents very limited insights into active collaborative learning and student's performance (Ansari \& Khan, 2020). Besides, there is lack of studies and growing interest towards the social media usage and active collaborative learning and its impact on students engagement, satisfaction, and learning performance (Waleed Mugahed Al-Rahmi et al., 2018). Therefore, the present study aims to investigate the effects of social use on active collaborative learning. In addition, how it improves the education of higher level students and how active learning leads to student engagement, satisfaction, and learning performance.

\section{LITERATURE REVIEW}

\subsection{Social Media use in HIGHER EDUCATION}

Social media adoption and its usage is become a growing body of interest, where attention is given and widely recognized by scholars and practitioners as a mechanism for driving, reshaping communication and interaction in developing countries (Ali Qalati et al., 2021; Barfi et al., 2021; Sikander Ali Qalati et al., 2021). In addition, social media usage has emerged as one of the most useful tool, if not the most useful, for improving the learning process, supporting collaboration, sharing of information and interaction between students and tutors, improving student experience, building cordial relationships among peers, and also a reliable medium that facilitates the effectiveness of distance learning (Awidi et al., 2019; Manca, 2020; Sobaih \& Moustafa, 2016). Previously, studies evidenced that academic staff used social media for professional development, gaining training, participating in discussion, attend conferences, and for teaching purposes (Prestridge, 2019).Prior literature has explored the networks frequently used as social media platforms, like Facebook, Twitter, Myspace, WhatsApp, and YouTube. However, the most widely used are Facebook and WhatsApp (Manca, 2020). Apart from the above, few studies examined the social media policies in higher education context and it's been discovered that social media offers significant ways to promote staff and students learning process (Alharthy et al., 2020; Diamond, 2017; Harlow, 2021; Pomerantz et al., 2015).

\subsection{Hypotheses development}

\subsubsection{Social media use and student engagement,} satisfaction, and learning performance

Student engagement in the context of social media illustrate their mental and physical engagement and time spent on interaction and an enhancement of educational excellency (Sobaih \& Moustafa, 2016). Student involvement when interacting with instructor and peers increased and it's in the same direction as when sharing information and ideas (Kumar \& Nanda, 2019). Students engagement in relation to the use of social media is an active state that is influenced by its usage (Waleed Mugahed Al-Rahmi et al., 2018). Many scholars and practitioners have shown interest in the investigation of social media usage in an educational setting as it is purported to improve student's engagement. In this context, (Alshuaibi et al., 2018) also reports significant effect of social media usage to this effect - student engagement. In addition, (Koshkin et al., 2017) argued that higher educational institutions are giving importance to integrating social media tools 
into their practices to pitch student satisfaction. Through social media usage, students can satisfy both academic and social needs simultaneously (PunyanuntCarter et al., 2017). (Jarman et al., 2021a) recently lays claims on the positive correlations between social media usage and student satisfaction among Australian students. Not limited to the aforementioned scholars that have argued that social media usage leads to improvement in learning performance, in the study, (Tur \& Marín, 2015) conducted study in Spain, where it's stated that most of the students felt that the use of social media was able to enable them to better understand course contents and make them learned and enjoy from the activities presented. Likewise, (Alshuaibi et al., 2018) study includes a sample of 227 business students concurring the significant effect of social media usage on students' academic performance in Malaysia. Although, a number of studies have been conducted to explore the effect of social media use, there is a continuing call from above studies to empirically test the relationship and support the existing literature in the context of higher level education. Thus, it's hypothesized that

H1-3: There is significant effect of social media use on student engagement, satisfaction, and learning performance.

\subsubsection{Social media use on active collaborative learning}

Collaborative learning refers to "instructional activities in which both learners and instructors engage in a common task where both the learner and the instructor, individually depend on and are accountable to each other, and is placed on an equal footing in working together" (Gogus, 2012). (Chen, 2015) argued that social media tools are as most important as learning aims in the way that they necessitate to have entailing interacting learning, social presence, and supporting active collaborative learning. Similarly (Zhu, 2012) evidenced that social applications and networking sites improve the constructions and collaboration of knowledge. In addition, (Waleed Mugahed Al-Rahmi et al., 2018) recently identified the social media tool as one of antecedents of active collaborative learning and found that consequences of it includes student's engagement, performance. Social media tools are seen as a channel for collaboration, transmitting information, interaction, and knowledge sharing between participants (Waleed Mugahed AlRahmi \& Zeki, 2017). Recently (Ansari \& Khan, 2020) highlighted the importance of active collaboration in the context of developing countries and found that social media used for collaborative learning had a significant influence on interactivity with peers, teachers and online knowledge behavior. In addition, the authors call for future studies to explore how social media use influences active collaboration learning in developing countries. Furthermore, (Sarwar et al., 2019) also researched that web-based application acts as a dynamic tool to accelerate the improvement of learning environment by promoting cooperation and communication among the students which improves their performance and learning. Thus, it's hypothesized that

H4: There is significant effect of social media use on active collaboration learning.

2.2.3 Active collaboration learning, student's engagement, satisfaction, and learning performance.

Active learning refers to the concept of engaging students to perform things and realize what they are actually doing (Qureshi et al., 2021). In other word, active learning is a process where students conscientiously engage in receiving and using knowledge imparted to full capacity and to yield desired results. Active learning requires a consuming amount of student engagement in the learning process, not limited to listening to instructions, reading, but also comprises students participation in presentation, class meetings, discussion and involvement in other events pertaining to their academic course (Hamouda \& Tarlochan, 2015). P (Waleed Mugahed Al-Rahmi et al., 2018; Waleed Mugahed Al-Rahmi \& Zeki, 2017; Ansari \& Khan, 2020; McDonough \& Foote, 2015; Qureshi et al., 2021).Previous studies give information that active learning associates with student engagement, and the method of stimulation that involves student participating actively in the learning process. (W Mugahed Al-Rahmi et al., 2015; Hyun et al., 2017) proves that active learning process leads to students satisfaction. Likewise, (Waleed Mugahed AlRahmi et al., 2018) recently found the significant impact of active learning on students satisfaction in Malaysia. (Stowell \& Nelson, 2007) argued that the impact of active learning on students' performance can be improved when combined with the use of new technological platforms of which social media networks are of no exemption and what this study seeks to explore. Thus, (Blasco-Arcas et al., 2013) empirically tests a conceptual model and stated that student engagement, satisfaction and performance are results of active learning. More so, (Kulikovskikh et al., 2017) studies the impact of encouraging collaborative learning in student learning performance, and observed and reported that active learning encourages students to disseminate information, and enable them to foster a more positive turnout in performance . Similarly (Chan et al., 2019) recently throws light on the significant effect of active learning 
on students learning performance in same regard. Thus, based on the above discussion, it's hypothesized that

H5-7: There is a significant effect of active collaborative learning on student engagement, satisfaction, and learning performance.

\section{METHODOLOGY}

\subsection{Research model}

Figure 1 shows the proposed model, which consists of two independent variables namely social media use and active collaborative learning, while student engagement, satisfaction, and learning performance are dependent variables. This model exhibits variables that aim at investigating the impact of social media use and active collaborative learning on student engagement, satisfaction, and learning performance. Also, an illustration of the impact of social media use on active collaborative learning in higher level education.

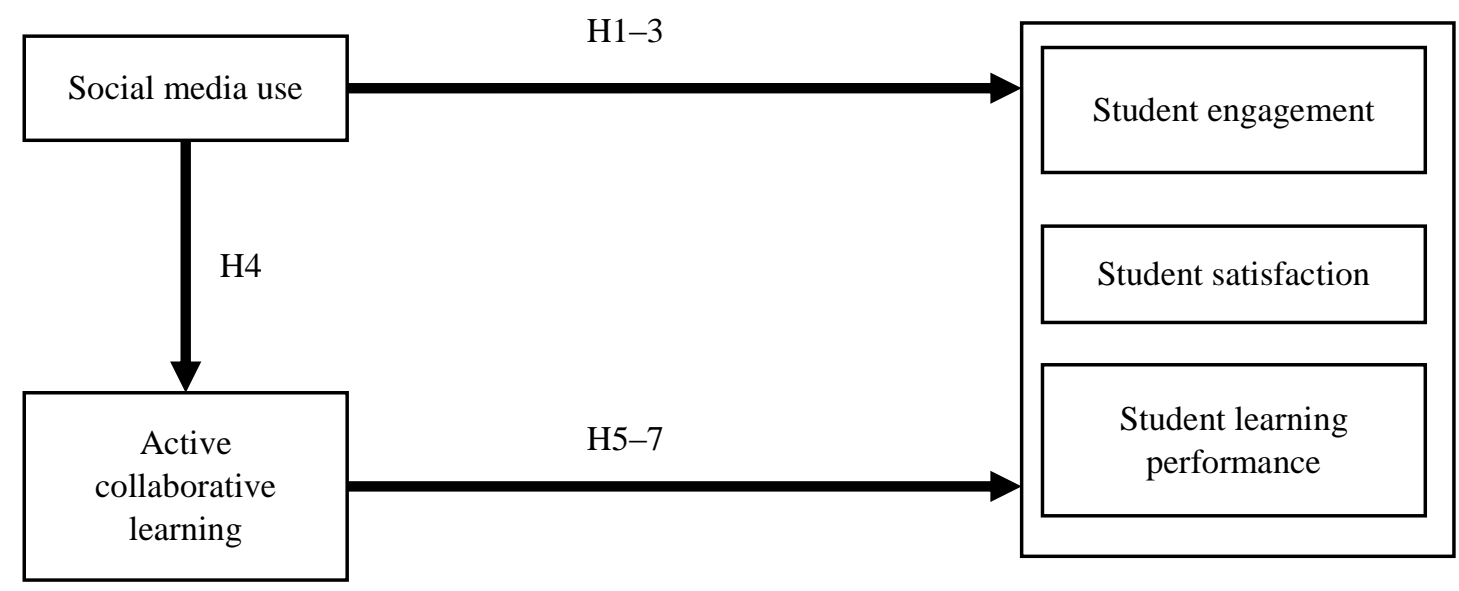

Figure 1. Conceptual framework

\subsection{Sampling and data collection}

In the present study, the quantitative method of data collection is been used and 600 questionnaires administered with an online web-based survey generated through Google forms and a link shared through social media platforms (i.e., WhatsApp, Email, Facebook) based on convenience sampling approach to undergraduate, graduate and postgraduate students. Due to current COVID-19 pandemic, web-based survey is widely used and offers benefits of low cost, maximum reach, minimum time consumption and more extensively interactive means (Qureshi et al., 2021).

The data collection link was open for a month, after construction and completion. Out of the 600 shared questionnaires, 429 valid answered questionnaire were received, which represents $71.5 \%$ response rate. Table 1 exhibits participants information, which states that $46.15 \%$ of students were females and over half of them $53.84 \%$ were male. Majority of them $32.4 \%$ were aged between 21 and 25 years and $42.8 \%$ had undergraduate level education (refer Table 1).

Table 1. Participant's information

\begin{tabular}{l|l|c|c}
\hline \multicolumn{2}{l|}{ Demographic items } & Frequency & Percentage \\
\hline Gender & Female & 198 & 46.154 \\
\hline & Male & 231 & 53.846 \\
\hline Age & $\leq 20$ & 116 & 27.040 \\
\hline & $21-25$ & 139 & 32.401 \\
\hline & $26-30$ & 123 & 28.671 \\
\hline & $>30$ & 51 & 11.888 \\
\hline
\end{tabular}




\begin{tabular}{l|l|c|c}
\hline Education & Undergraduate & 184 & 42.890 \\
\hline & Graduate & 172 & 40.093 \\
\hline & Postgraduate & 73 & 17.016 \\
\hline
\end{tabular}

\subsection{Measurement and data analysis tools}

The items of this study were measured using 5pint Likert scale, where 1 represents strongly disagree and 5 strongly agree.

\subsubsection{Measures of the study}

Social media use: was measured using three items adopted from (W Mugahed Al-Rahmi et al., 2015; Sarwar et al., 2019). A sample item includes "I use social media for academic purposes to discuss and share my ideas; I use social media to complete my academic tasks".

Active collaborate learning: was measured using four items adopted from (Blasco-Arcas et al., 2013). A sample item for this construct includes "I felt that I actively collaborated in my learning experience; I felt that I had freedom to participate in my own learning experience".

Student engagement: was assessed through five items adopted from (Waleed Mugahe Al-Rahmi \& Othman, 2013; Molinillo et al., 2018). A sample item includes "The collaborative work is fun; I enjoyed thinking about the collaborative work; Learning is interesting to me".

Student satisfaction: seven items were used to measure this construct. The item for this construct adopted from (Waleed Mugahe Al-Rahmi \& Othman, 2013). A sample item includes "I really like working in collaborative groups with my teammates; I have benefited from interacting with my teammates".

Student learning performance: was assessed using three items adopted from (MacGeorge et al., 2008). A sample item includes "I gain knowledge through collaborative work; I develop skills through collaborative work".

\subsubsection{Data analysis techniques}

This study used a statistical package for social science for demographical information i.e., gender, age, education level frequencies and their percentages. In addition, partial least square structural equation modeling (PLS-SEM) using SmartPLS 3.3 software was used for inferential statistics both statistical software and their techniques are widely used and applicable across the fields.

\section{RESULT ANALYSIS AND DISCUSSION}

SmartPLS 3.3 software was used to analyze the data collected. For defined results, the proposed framework, PLS-SEM was used to assess the measurement and structural model suggested by (Hair et al., 2019).

\subsection{The Measurement Model}

The relationship between latent constructs and their respective measure is examined in the measurement model. The quality of measurement model was assessed using several validity and reliability tests (Hair et al., 2019). (Qureshi et al., 2021) suggested that assessment of measurement model comprises of two segments; convergent and discriminant validity. Table 2 illustrates individual factor loading of all constructs and were retained between the acceptable threshold 0.70-0.95 (Fang et al., 2021). Besides the convergent validity was measured using Cronbach's alpha (CA), composite reliability (CR) and the average variance extracted (AVE). The CA was employed to measure the scale reliability, which is retained between 0.793 and 0.933 greater than acceptable threshold 0.7 (Hair et al., 2019). In addition, internal consistency of the constructs assessed through CR which retained between 0.866 and $0.957>0.70$ acceptable threshold. Besides, AVE also used to assess the convergent validity, the value of AVE for this study retained between 0.614 and 0.882 , which is greater than acceptable threshold 0.5 (Fornell \& Larcker, 1981).

Furthermore, this study measured discriminant validity using AVE and Heterotrait-Monotrait ratio (HTMT). This validity identify the extent to how much a latent construct differs from other constructs and it's investigated through (Fornell \& Larcker, 1981) test, which estimates that the first value of every variable must be bold as it indicates the square root of AVE and is considered adequate only when diagonal values are higher than non-diagonal values in the related rows and columns. Table 3 results show that the present study related to discriminant validity adequately satisfied the relative standards (Fornell \& Larcker, 1981). Moreover, in relation to HTMT, this value shows that all values of the constructs are less than acceptable threshold $\mathrm{HTMT}_{0.85}$ (Hair et al., 2019) (refer Table 4). 
EPRA International Journal of Multidisciplinary Research (IJMR) - Peer Reviewed Journal Volume: 7| Issue: 9| September 2021|| Journal DOI: 10.36713/epra2013 || SJIF Impact Factor 2021: 8.047 || ISI Value: 1.188

Table 2. Assessment of Measurement Model

\begin{tabular}{|c|c|c|c|c|c|c|}
\hline Construct & Item code & Loading & $\mathbf{C A}$ & $\mathbf{C R}$ & AVE & VIF \\
\hline \multirow[t]{3}{*}{ Social media use (SMU) } & SMU1 & 0.938 & 0.92 & 0.949 & 0.862 & 3.12 \\
\hline & SMU2 & 0.917 & & & & 2.978 \\
\hline & SMU3 & 0.929 & & & & 2.991 \\
\hline \multirow[t]{4}{*}{ Active collaborative learning (ACL) } & ACL1 & 0.725 & 0.793 & 0.866 & 0.619 & 1.486 \\
\hline & ACL2 & 0.829 & & & & 1.969 \\
\hline & ACL3 & 0.83 & & & & 2.05 \\
\hline & ACL4 & 0.758 & & & & 1.593 \\
\hline \multirow[t]{4}{*}{ Student engagement (SE) } & SE1 & 0.897 & 0.915 & 0.94 & 0.797 & 2.969 \\
\hline & SE2 & 0.888 & & & & 2.813 \\
\hline & SE3 & 0.897 & & & & 2.938 \\
\hline & SE4 & 0.889 & & & & 2.735 \\
\hline \multirow[t]{6}{*}{ Student satisfaction (SS) } & SS1 & 0.74 & 0.874 & 0.905 & 0.614 & 1.623 \\
\hline & SS2 & 0.723 & & & & 1.626 \\
\hline & SS3 & 0.808 & & & & 2.162 \\
\hline & SS4 & 0.847 & & & & 2.498 \\
\hline & SS5 & 0.804 & & & & 2.152 \\
\hline & SS6 & 0.774 & & & & 1.976 \\
\hline \multirow[t]{3}{*}{ Student learning performance (SLP) } & SLP1 & 0.942 & 0.933 & 0.957 & 0.882 & 1.663 \\
\hline & SLP2 & 0.937 & & & & 3.012 \\
\hline & SLP3 & 0.938 & & & & 3.122 \\
\hline
\end{tabular}

Table 3. Discriminant validity (Fornell-Larcker-criterion)

\begin{tabular}{l|c|c|c|c|c}
\hline & ACL & SMU & SE & SLP & SS \\
\hline ACL & 0.787 & & & & \\
\hline SMU & 0.631 & 0.928 & & & \\
\hline SE & 0.604 & 0.575 & 0.893 & & \\
\hline SLP & 0.625 & 0.614 & 0.558 & 0.939 & \\
\hline SS & 0.621 & 0.59 & 0.726 & 0.713 & 0.784 \\
\hline
\end{tabular}

Table 4. Discriminant validity (HTMT-criterion)

\begin{tabular}{l|c|c|c|c|c}
\hline & ACL & SMU & SE & SLP & SS \\
\hline ACL & & & & & \\
\hline SMU & 0.739 & & & & \\
\hline SE & 0.708 & 0.626 & & & \\
\hline SLP & 0.727 & 0.663 & 0.604 & & \\
\hline SS & 0.745 & 0.657 & 0.811 & 0.79 & \\
\hline
\end{tabular}

\subsection{The Structural Model}

The assessment of structural model is the second approach of PLS-SEM, it indicates the relationship between the constructs (Qureshi et al., 2021). Based on
PLS path modeling existing literature (Alshuaibi et al. 2018; Fang et al., 2021; Hair et al., 2019; Henseler et al., 2009) four measures were used in structural model testing, namely, path coefficient, coefficient of 
determination $\left(\mathrm{R}^{2}\right)$, effect $\operatorname{size}\left(\mathrm{f}^{2}\right)$ and predictive relevance $\left(\mathrm{Q}^{2}\right)$. This study uses bootstrapping techniques with 5000 subsample to generate path coefficient and their level of significance. Table 5 shows that all of the hypotheses were supported based on the criterion ( $p$-value $<0.05, t$-value $>1.96)$. Among these hypotheses social media use has the strongest influence on active collaborative learning (Beta=0.631). Figure 2 also indicates the relationship between constructs along with path coefficient and their level of significance.

Regarding the $\mathrm{R}^{2}$ value, (Cohen, 1992) suggested that $0.19,0.33$, and 0.60 are considered weak, moderate and substantial, respectively. Table 5 results states that this study has moderate level of explaining power, as value are found between 0.399 and 0.471 , which is greater than 0.33 , while less than
0.60 (Cohen, 1992). $\mathrm{R}^{2}$ value 0.399 states that social media use explains $39.9 \%$ changes in active collaborative learning. Furthermore, related to effect size (Cohen, 1992) explained the $\mathrm{f}^{2}$ values of 0.35 , 0.15 , and 0.02 have large, medium, and weak effects respectively. Table 5 shows that $\mathrm{f}^{2}$ value for social media usage on student engagement and satisfaction is weak, while on student learning it's medium and on active collaborative learning it's large. Regarding the predictive relevance $\mathrm{Q}^{2}$ a cross validated redundancy measure was suggested by (Henseler et al., 2009). It is proposed that the model has a predictive relevance if $\mathrm{Q}^{2}$ value is greater than zero (refer Table 5). (Hair et al., 2019; Henseler et al., 2009) suggested standardized root mean square residual (SRMR) to test the goodness of fit. In our study SRMR is 0.046 , which falls below the acceptable threshold 0.08 (Hair et al., 2019).

Table 5. Hypotheses testing, $R^{2}, f^{2}$, and $Q^{2}$

\begin{tabular}{l|l|c|c|c|c|c}
\hline Hypotheses & Relationships & $\begin{array}{c}\text { Path } \\
\text { coefficient }\end{array}$ & SD & $\boldsymbol{t}$-value & Decision & $\begin{array}{c}\text { Effect } \\
\text { size } \\
\left(\mathbf{f}^{2}\right)\end{array}$ \\
\hline $\mathrm{H} 1$ & Social media use $\rightarrow$ Student engagement & 0.322 & 0.053 & $6.03^{*}$ & Supported & 0.109 \\
\hline $\mathrm{H} 2$ & Social media use $\rightarrow$ Student satisfaction & 0.329 & 0.055 & $5.956^{*}$ & Supported & 0.118 \\
\hline $\mathrm{H} 3$ & $\begin{array}{l}\text { Social media use } \rightarrow \text { Student learning } \\
\text { performance }\end{array}$ & 0.366 & 0.048 & $7.56^{*}$ & Supported & 0.152 \\
\hline $\mathrm{H} 4$ & $\begin{array}{l}\text { Social media use } \rightarrow \text { Active collaborative } \\
\text { learning }\end{array}$ & 0.631 & 0.036 & $17.418^{*}$ & Supported & 0.663 \\
\hline $\mathrm{H} 5$ & $\begin{array}{l}\text { Active collaborative learning } \rightarrow \text { Student } \\
\text { engagement }\end{array}$ & 0.400 & 0.05 & $8.03^{*}$ & Supported & 0.168 \\
\hline $\mathrm{H} 6$ & $\begin{array}{l}\text { Active collaborative learning } \rightarrow \text { Student } \\
\text { satisfaction }\end{array}$ & 0.413 & 0.055 & $7.549 *$ & Supported & 0.187 \\
\hline $\mathrm{H} 7$ & $\begin{array}{l}\text { Active collaborative learning } \rightarrow \text { Student } \\
\text { learning performance }\end{array}$ & 0.394 & 0.048 & $8.14^{*}$ & Supported & 0.176 \\
\hline
\end{tabular}

Note: Critical values. * t-value $>1.96(\mathrm{p}<0.05)$

$\mathbf{R}^{2}$ (Student engagement $)=0.427$; (Student satisfaction $)=0.451$; $($ Student learning performance $)=0.471$; and (Active collaborative learning) $=0.399$

$\mathbf{Q}^{2}$ (Student engagement) $=0.318 ;($ Student satisfaction $)=0.257$; (Student learning performance $)=0.391$ and

(Active collaborative learning) $=0.232$

Goodness of fit summary: SRMR $=0.046$ 


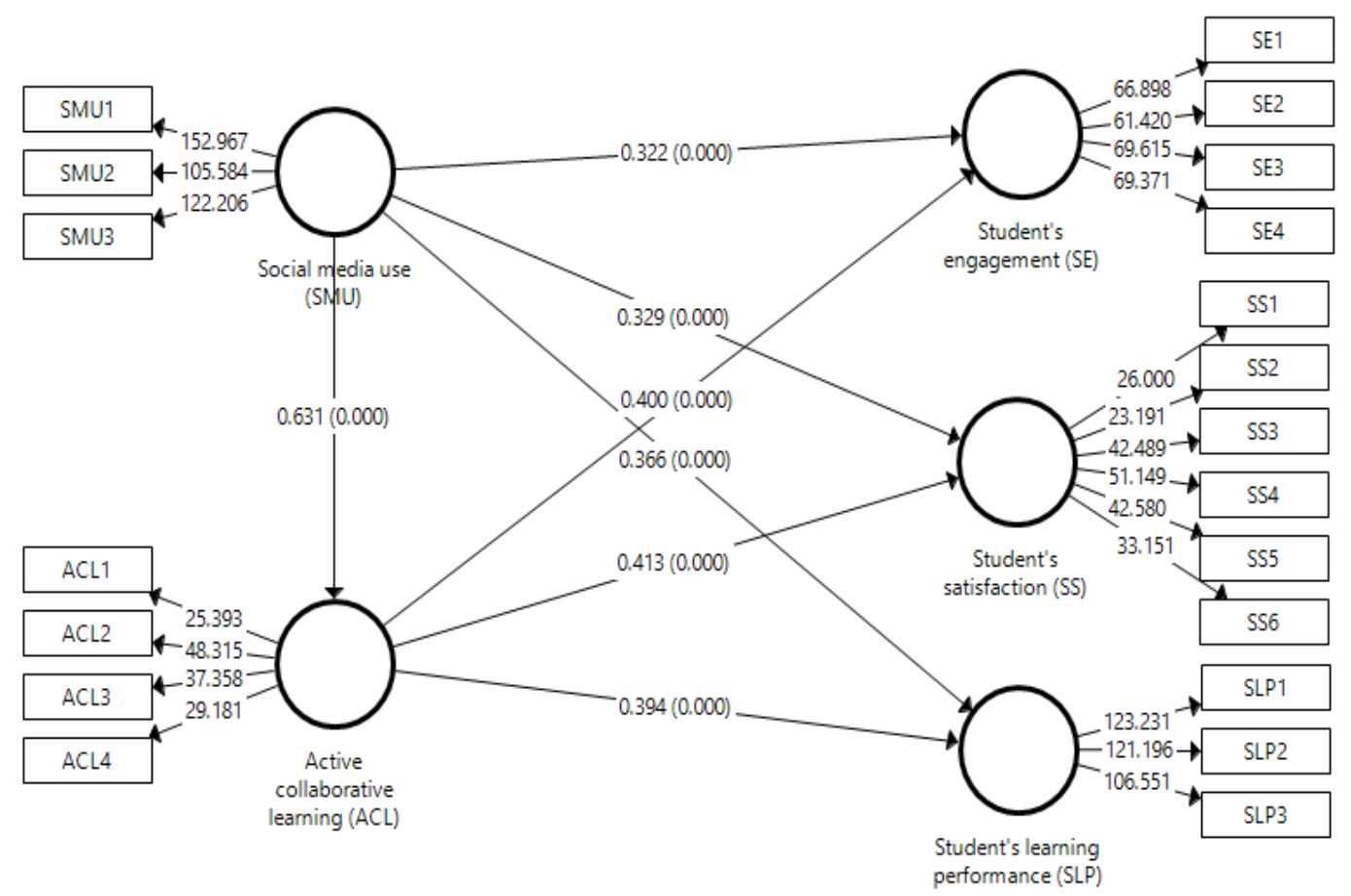

Figure 2. Structural equation modeling

\subsection{Discussion}

This study uses PLS-SEM for analysis for testing the hypotheses. The results of the study shows that all of the hypotheses were supported given that their $\mathrm{p}$-value $<0.05$ and $\mathrm{t}$-value $>1.960$.

The first hypothesis is in relation to social media use and student engagement. This study shows the positive and significant relationship between social media use and student's engagement $(\beta=0.322$, $\mathrm{p}=0.000$ ); thus, $H 1$ is supported. This finding infers that if social media usage increase by 1 unit, student engagement will increase by $32.2 \%$. This finding is in line with previous work of (Alshuaibi et al., 2018).

Regarding the second hypothesis about social media use and student satisfaction. This study confirmed the positive and significant effect of social media use on student satisfaction among higher level education in Ghana $(\beta=0.329, \mathrm{p}=0.000)$; thus, $H 2$ is supported. This result infers that social media usage will bring $32.9 \%$ change in student satisfaction if increased by a unit. This study's finding is supported by (Jarman et al., 2021b; Punyanunt-Carter et al., 2017) who also found the significant effect and correlation between social media use on student satisfaction.

Related to third hypothesis, this study results shows that there's a positive and significant impact of social media use on student learning performance ( $\beta=0.366, \mathrm{p}=0.000$ ); thus, $H 3$ is supported. This finding implies that a single unit change in social media use has a $36.6 \%$ change in student learning performance. This result suggests that social media use has the strongest influence on learning performance relative to student engagement and satisfaction. This finding is harmonious to (Alshuaibi et al., 2018) who concludes that using social media increase the student learning performance.

The fourth hypothesis is about the association between social media usage and active collaborative learning. The present study results show that there is a positive and significant relationship between social media usage and active collaborative learning $(\beta=0.631, \mathrm{p}=0.000)$; thus, $H 4$ is supported. This findings suggest that social media is responsible for $63.1 \%$ change in active collaborative learning. This result is consistent with (Waleed Mugahed Al-Rahmi et al., 2018; Ansari \& Khan, 2020; Qureshi et al., 2021) studies concluding that social media use enables students to collaborate and interact.

Regarding the fifth hypothesis, this study confirmed the positive and significant influence of active collaborative learning on student engagement ( $\beta=0.400, p=0.000$ ); thus, $H 5$ is supported. This finding suggests that students can access more information and academic resources via collaborative learning and engagement. Besides, this result infers that a single unit change in active collaborative learning leads to a $40 \%$ change in student engagement. This finding is in line with previous work of (Waleed Mugahed Al-Rahmi et 
al., 2018; Waleed Mugahed Al-Rahmi \& Zeki, 2017; Ansari \& Khan, 2020; McDonough \& Foote, 2015; Qureshi et al., 2021) which concludes that active collaborative learning increases student engagement.

The sixth hypothesis was constructed with regards to the relationship between active collaborative learning and student satisfaction. The result proves the positive and significant effect of active collaborative learning on student's satisfaction $(\beta=0.413, \mathrm{p}=0.000)$; thus, $H 6$ is supported. The finding suggest that the better the extent of collaboration, the more student satisfaction will be. In addition, this result infers that a single unit change in active collaborative learning leads to $41.3 \%$ change in student's satisfaction. This result is consistent with (Waleed Mugahed Al-Rahmi et al., 2018) study which also confirmed the significant effect of student's satisfaction.

Regarding the seventh hypothesis, this study confirmed the positive and significant effect of active collaborative learning on student learning performance ( $\beta=0.394, \mathrm{p}=0.000$ ); thus, $H 7$ is supported. This result state that if active collaborative learning increase by 1 unit, student learning performance will increase by 39.4\%. This finding is consistent with (Chan et al., 2019; Kulikovskikh et al., 2017) which concludes that active collaborative learning improves the student's learning performance.

\section{CONCLUSION}

Social media usage is growing and gaining attention across the sectors, since it has greatly changed the way of communication, collaboration and interaction with other. This study objective to investigate the how social media use improve higher education among Ghanaian high level students and the effect of social media and active collaborative learning on their engagement, satisfaction, and learning performance. To the education sector, it offers variety of benefits including access to more research opportunities for postgraduate students, improved communication and networking with students and colleagues, increased willingness to share information and publish, access to experienced researchers, facilitate and support learning and teaching, etc. Despite the benefits offered, there are several challenges of social media use in education such as lack of trust, unclear benefits to participants, security and privacy concerns, low interest and awareness, inadequate training and skills, and distorted management of time to learn and use new platforms (Chugh et al., 2021).

In order to meet the objectives of the study, the quantitative approach was adopted and data was collected through online survey. The use of PLS-SEM in this present study shows that all of the hypotheses were supported based on criterion $p$-value $<0.05$. This study's results provide an understanding about student's engagement, satisfaction, and learning performance and their relationship with social media usage and active collaboration. Of seven hypotheses, the results indicate that social media usage has the strongest influence on active collaborative learning (beta $=0.631$ ).

\subsection{Implications}

This study also offers certain implications for the practitioners and academic institutions. Higher level educational institutions must motivate their academic staff to employ social media and active collaborative learning practices in their teaching styles to improve student engagement, satisfaction, and learning performance when constructing academic curriculum (Waleed Mugahed Al-Rahmi et al., 2018; Ansari \& Khan, 2020). In educational institutions, where collaborative learning is not as common, as a result of the COVID-19 global pandemic, yet it is one of the main concerns of teachers in developing countries to adjust and modify the traditional way of teaching and learning into an advanced updated online- based method of teaching and learning. With effect, online students can collaborate easily via social media which can affect learning performance (Qureshi et al., 2021). Furthermore, instructors must guide students to use social media for collaborative learning as it provides a more conducive e - learning environment for. Notwithstanding that, it improves the learning environment by providing student engagement, satisfaction, collaboration, interaction and by allowing group discussion about research projects at the core as well as other developmental yet educational resources. Indeed, students utilize social media tools for collaboration with colleagues, teammates, and tutors and exchange information which develop learning,

\subsection{Limitation and Future Research}

This study is not free from the limitations, implying that there avenues for the future studies. To start with, the study was conducted in the context of higher level education. Therefore, this study's results cannot be generalized and implemented on in an alllevel educational standard. Thus, it is suggested that future scholars may replicate this study in school level education. Also, this study was conducted in a geographic educational context of a developing country. Therefore, future studies sample should be targeted at developed countries for enriching the generalizability of outcomes. Furthermore, data was 
collected from cross-sectional online survey; therefore, caution must be taken while inferring basic relationship. To address this challenge, it is suggested that future studies accumulate data through in person surveys and observations for validating proposed model. Lastly, this study shows more of the direct effect of social media and active collaborative learning on student's engagement, satisfaction, and performance. Contrary to that, active collaborative learning can mediate the relationship between social media usage and students learning performance (Qureshi et al., 2021). Thus, it is suggested that future studies investigate the mediating role of active collaborative learning.

\section{REFERENCE}

1. Al-Daihani, S. M., Al-Qallaf, J. S., \& AlSaheeb, S. A. (2018). Use of social media by social science academics for scholarly communication. Global Knowledge, Memory and Communication, 67(6/7), 412-424. doi:10.1108/GKMC-11-2017-0091

2. Al-Rahmi, W. M., Alias, N., Othman, M. S., Marin, V. I., \& Tur, G. (2018). A model of factors affecting learning performance through the use of social media in Malaysian higher education. Computers \& Education, 121, 59-72. doi:https://doi.org/10.1016/j.compedu.2018.02.010

3. Al-Rahmi, W. M., \& Othman, M. S. (2013). Evaluating student's satisfaction of using social media through collaborative learning in higher education. International Journal of advances in engineering \& technology, 6(4), 1541.

4. Al-Rahmi, W. M., Othman, M. S., \& Yusuf, L. M. (2015). Effect of engagement and collaborative learning on satisfaction through the use of social media on Malaysian higher education. Research Journal of Applied Sciences, Engineering and Technology, 9(12), 1132-1142.

5. Al-Rahmi, W. M., \& Zeki, A. M. (2017). A model of using social media for collaborative learning to enhance learners' performance on learning. Journal of King Saud University - Computer and Information Sciences, 29(4), 526-535. doi:https://doi.org/10.1016/j.jksuci.2016.09.002

6. Aldahdouh, T. Z., Nokelainen, P., \& Korhonen, V. (2020). Technology and Social Media Usage in Higher Education: The Influence of Individual Innovativeness. SAGE Open, 10(1), 2158244019899441. doi:10.1177/2158244019899441

7. Alharthy, F., Wang, Y., \& Dudley, A. (2020). An Analysis of the Current Policies for Social Media Use in Saudi Higher Education. Paper presented at the International Conference on Human-Computer Interaction.
8. Ali Qalati, S., Li, W., Ahmed, N., Ali Mirani, M., \& Khan, A. (2021). Examining the Factors Affecting SME Performance: The Mediating Role of Social Media Adoption. Sustainability, 13(1), 75. Retrieved from https://www.mdpi.com/20711050/13/1/75

9. Alshuaibi, M. S. I., Alshuaibi, A. S. I., Shamsudin, F. M., \& Arshad, D. A. (2018). Use of social media, student engagement, and academic performance of business students in Malaysia. International Journal of Educational Management, 32(4), 625640. doi:10.1108/IJEM-08-2016-0182

10. Ansari, J. A. N., \& Khan, N. A. (2020). Exploring the role of social media in collaborative learning the new domain of learning. Smart Learning Environments, 7(1), 9. doi:10.1186/s40561-02000118-7

11. Awidi, I. T., Paynter, M., \& Vujosevic, T. (2019). Facebook group in the learning design of a higher education course: An analysis of factors influencing positive learning experience for students. Computers \& Education, 129, 106-121. doi:https://doi.org/10.1016/j.compedu.2018.10.018

12. Barfi, K. A., Bervell, B., \& Arkorful, V. (2021). Integration of social media for smart pedagogy: initial perceptions of senior high school students in Ghana. Education and Information Technologies, 26(3), 3033-3055. doi:10.1007/s10639-020-10405$y$

13. Blasco-Arcas, L., Buil, I., Hernández-Ortega, B., \& Sese, F. J. (2013). Using clickers in class. The role of interactivity, active collaborative learning and engagement in learning performance. Computers \& Education, $\quad 62, \quad 102-110$. doi:https://doi.org/10.1016/j.compedu.2012.10.019

14. Chan, S. C. H., Wan, C. L. J., \& Ko, S. (2019). Interactivity, active collaborative learning, and learning performance: The moderating role of perceived fun by using personal response systems. The International Journal of Management Education, 17(1), 94-102. doi:https://doi.org/10.1016/j.ijme.2018.12.004

15. Chen, Y.-c. (2015). Linking learning styles and learning on mobile Facebook. International review of research in open and distributed learning, 16(2), 94-114.

16. Chugh, R., Grose, R., \& Macht, S. A. (2021). Social media usage by higher education academics: $A$ scoping review of the literature. Education and Information Technologies, 26(1), 983-999. doi:10.1007/s10639-020-10288-z

17. Cohen, J. (1992). Statistical power analysis. Current directions in psychological science, 1(3), 98-101. 
18. Department, S. R. (2021). Number of global social network users 2017-2025 Retrieved from https://www.statista.com/statistics/278414/numberof-worldwide-social-network-users/

19. Deshpande, S., \& Shesh, A. (2021, 2021//). Blended Learning and Analysis of Factors Affecting the Use of ICT in Education. Paper presented at the Next Generation Information Processing System, Singapore.

20. Diamond, A. (2017). Social media policies and academic freedom: Higher education Faculty and administrator perceptions. Concordia University (Oregon),

21. Fang, G. G., Qalati, S. A., Ostic, D., Shah, S. M. M., \& Mirani, M. A. (2021). Effects of entrepreneurial orientation, social media, and innovation capabilities on SME performance in emerging countries: a mediated-moderated model. Technology Analysis \& Strategic Management, 113. doi:10.1080/09537325.2021.1957816

22. Fornell, C., \& Larcker, D. F. (1981). Evaluating structural equation models with unobservable variables and measurement error. Journal of marketing research, 18(1), 39-50.

23. Gogus, A. (2012). Active Learning. In N. M. Seel (Ed.), Encyclopedia of the Sciences of Learning (pp. 77-80). Boston, MA: Springer US.

24. Hair, J. F., Risher, J. J., Sarstedt, M., \& Ringle, C. M. (2019). When to use and how to report the results of PLS-SEM. European Business Review, 31(1), 2-24. doi:10.1108/EBR-11-2018-0203

25. Hamouda, A., \& Tarlochan, F. (2015). Engaging engineering students in active learning and critical thinking through class debates. Procedia-Social and Behavioral Sciences, 191, 990-995.

26. Harlow, S. (2021). Protecting News Companies and Their Readers: Exploring Social Media Policies in Latin American Newsrooms. Digital Journalism, 9(2), 176-195.

27. Henseler, J., Ringle, C. M., \& Sinkovics, R. R. (2009). The use of partial least squares path modeling in international marketing. In $R$. $R$. Sinkovics \& P. N. Ghauri (Eds.), New Challenges to International Marketing (Vol. 20, pp. 277-319): Emerald Group Publishing Limited.

28. Hyun, J., Ediger, R., \& Lee, D. (2017). Students' Satisfaction on Their Learning Process in Active Learning and Traditional Classrooms. International Journal of Teaching and Learning in Higher Education, 29(1), 108-118.

29. Jarman, H. K., Marques, M. D., McLean, S. A., Slater, A., \& Paxton, S. J. (2021a). Motivations for Social Media Use: Associations with Social Media Engagement and Body Satisfaction and Well-Being among Adolescents. Journal of Youth and Adolescence. doi:10.1007/s10964-020-01390-z

30. Jarman, H. K., Marques, M. D., McLean, S. A., Slater, A., \& Paxton, S. J. (2021b). Social media, body satisfaction and well-being among adolescents: A mediation model of appearanceideal internalization and comparison. Body Image, 36 , 139-148. doi:https://doi.org/10.1016/j.bodyim.2020.11.005

31. Koshkin, A. P., Rassolov, I. M., \& Novikov, A. V. (2017). Monitoring social media: Students satisfaction with university administration activities. Education and Information Technologies, 22(5), 2499-2522. doi:10.1007/s10639-016-9558-x

32. Kulikovskikh, I. M., Prokhorov, S., \& Suchkova, S. (2017). Promoting collaborative learning through regulation of guessing in clickers. Computers in Human Behavior, 75, 81-91.

33. Kumar, V., \& Nanda, P. (2019). Social media in higher education: A framework for continuous engagement. International Journal of Information and Communication Technology Education (IJICTE), 15(1), 97-108.

34. MacGeorge, E. L., Homan, S. R., Dunning, J. B., Elmore, D., Bodie, G. D., Evans, E., . . Lichti, S. M. (2008). The influence of learning characteristics on evaluation of audience response technology. Journal of Computing in Higher Education, 19(2), 25-46.

35. Manca, S. (2020). Snapping, pinning, liking or texting: Investigating social media in higher education beyond Facebook. The Internet and Higher Education, 44, 100707. doi:https://doi.org/10.1016/j.iheduc.2019.100707

36. Manca, S., \& Ranieri, M. (2016). Facebook and the others. Potentials and obstacles of Social Media for teaching in higher education. Computers \& Education, 95, 216-230. doi:https://doi.org/10.1016/j.compedu.2016.01.012

37. Manca, S., \& Ranieri, M. (2017). Implications of social network sites for teaching and learning. Where we are and where we want to go. Education and Information Technologies, 22(2), 605-622.

38. Maryanti, R., Nandiyanto, A. B. D., Hufad, A., \& Sunardi, S. (2021). Science education for students with special needs in Indonesia: From definition, systematic review, education system, to curriculum. Indonesian Journal of Community and Special Needs Education, 1(1), 1-8.

39. McDonough, K., \& Foote, J. A. (2015). The impact of individual and shared clicker use on students' collaborative learning. Computers \& Education, 86, 236-249.

40. Molinillo, S., Aguilar-Illescas, R., Anaya-Sánchez, R., \& Vallespín-Arán, M. (2018). Exploring the 
impacts of interactions, social presence and emotional engagement on active collaborative learning in a social web-based environment. Computers \& Education, 123, 41-52.

41. Montazer, G. A., \& Al-Rikabi, Y. K. (2021, 19-20 May 2021). Identifying the Obstacles of Implementing E-Learning in Iraqi Universities. Paper presented at the 2021 7th International Conference on Web Research (ICWR).

42. Pausé, C., \& Russell, D. (2016). Sociable scholarship: The use of social media in the 21st century academy.

43. Pomerantz, J., Hank, C., \& Sugimoto, C. R. (2015). The state of social media policies in higher education. PLoS One, 10(5), e0127485.

44. Prestridge, S. (2019). Categorising teachers' use of social media for their professional learning: A selfgenerating professional learning paradigm. Computers \& Education, 129, 143-158. doi:https://doi.org/10.1016/j.compedu.2018.11.003

45. Punyanunt-Carter, N. M., De La Cruz, J. J., \& Wrench, J. S. (2017). Investigating the relationships among college students' satisfaction, addiction, needs, communication apprehension, motives, and uses \& gratifications with Snapchat. Computers in Human Behavior, 75, 870-875. doi:https://doi.org/10.1016/j.chb.2017.06.034

46. Qalati, S. A., Ostic, D., Shuibin, G., \& Mingyue, F. (2021). A mediated-moderated model for social media adoption and small and medium-sized enterprise performance in emerging countries. Managerial and Decision Economics, n/a(n/a). doi:https://doi.org/10.1002/mde.3422

47. Qalati, S. A., Vela, E. G., Li, W., Dakhan, S. A., Hong Thuy, T. T., \& Merani, S. H. (2021). Effects of perceived service quality, website quality, and reputation on purchase intention: The mediating and moderating roles of trust and perceived risk in online shopping. Cogent Business \& Management, 8(1),

1869363. doi:10.1080/23311975.2020.1869363

48. Qalati, S. A., Yuan, L. W., Khan, M. A. S., \& Anwar, F. (2021). A mediated model on the adoption of social media and SMEs' performance in developing countries. Technology in Society, 64, 101513. doi:https://doi.org/10.1016/j.techsoc.2020.101513

49. Qureshi, M. A., Khaskheli, A., Qureshi, J. A., Raza, S. A., \& Yousufi, S. Q. (2021). Factors affecting students' learning performance through collaborative learning and engagement. Interactive Learning Environments, 1-21. doi:10.1080/10494820.2021.1884886

50. Sarwar, B., Zulfiqar, S., Aziz, S., \& Ejaz Chandia, K. (2019). Usage of social media tools for collaborative learning: The effect on learning success with the moderating role of cyberbullying. Journal of Educational Computing Research, 57(1), 246-279.

51. Sobaih, A. E. E., Hasanein, A. M., \& Abu Elnasr, A. E. (2020). Responses to COVID-19 in Higher Education: Social Media Usage for Sustaining Formal Academic Communication in Developing Countries. Sustainability, 12(16), 6520. Retrieved from https://www.mdpi.com/2071-1050/12/16/6520

52. Sobaih, A. E. E., \& Moustafa, M. A. (2016). Speaking the Same Language: The Value of Social Networking Sites for Hospitality and Tourism Higher Education in Egypt. Journal of Hospitality \& Tourism Education, 28(1), 21-31. doi:10.1080/10963758.2015.1127169

53. Stowell, J. R., \& Nelson, J. M. (2007). Benefits of electronic audience response systems on student participation, learning, and emotion. Teaching of psychology, 34(4), 253-258.

54. Tur, G., \& Marín, V. I. (2015). Exploring student teachers' attitudes and beliefs towards e-portfolios and technology in education. Exploring student teachers' attitudes and beliefs towards e-portfolios and technology in education, 57-82.

55. Zhu, C. (2012). Student satisfaction, performance, and knowledge construction in online collaborative learning. Journal of Educational Technology \& Society, 15(1), 127-136. 